\title{
59. Helping trusted messengers find their voice on climate change
}

\section{Edward Maibach}

Imagine this. You're a public health professional. Your entire career has been devoted to fighting some of humanity's most terrible afflictions: cancer, HIV/AIDS, addiction, and others. One day, suddenly, you come to recognize climate change as the most terrible of all afflictions threatening human health and well-being. What would you do? I suspect you would do - or have already done - as I did: refocus your life to help to avert a sustained global public health catastrophe from climate change. Anything less would feel like a betrayal of your most deeply held values.

It took nearly two decades for me to recognize climate change for what it truly is. It should have been immediately obvious, but it wasn't. That it took so long has given me insight and empathy for how difficult it can be for people to recognize that climate change is not only a threat to plants, penguins and polar bears, but also a profound threat to us, now and for countless generations to come. Helping reveal this truth has become my life's new work.

In fact, revealing truths about health has always been the focus of my work. Some of these truths are horrible (such as the pervasive lies told by the tobacco industry that have led to countless addictions, dreaded illnesses, and early deaths), and some have been wonderful (such as the safety and effectiveness of childhood vaccines). Trained in both public health and communication science, my work has always aimed to help people - members of the public, government officials, business leaders, civic leaders and others - have the information they need to make the best possible decisions about health - their health as well as the health of others.

Breathtaking gains have been made in human health worldwide over the past century. With each passing decade we've learnt more about the conditions that foster good health - including education, a living wage, sanitation services, clean air and water, nutritious food, physical activity, and immunizations - and most nations have made great progress in ensuring their people have access to these health-enhancing conditions. However, over the past two decades, public health experts have slowly come to realize that a stable climate 
is also fundamental to health because climate change harms people's health, and the ecosystems on which we depend, in many ways.

Like many Americans, I took note of the 1988 U.S. Congressional testimony by Dr. James Hansen of the NASA Goddard Space Institute warning about the dangers of human-caused climate change, and read many news accounts about climate change over the next two decades. In 2006, however, I had a sudden awakening. At the urging of a family member, my wife and I enrolled in a week-long study trip in the Alps. The trip director asked us to prepare for the trip by watching An Inconvenient Truth (the movie about Al Gore's climate education efforts) and reading The Weather Makers (a book about climate change by Australian scientist Tim Flannery).

The "study" portion of the trip was a series of climate change lectures addressing its causes, impact, risks and possible solutions presented over four days by two leading experts, John Schellnhuber and Ottmar Edenhofer of the Potsdam Institute for Climate Impact Research. Although John and Ottmar didn't directly address human health in their lectures, in the closing moments of their final lecture I had a moment of epiphany. In that instant, the horrible truth became clear: the long arc of human history would cease bending toward longevity, prosperity, and justice unless climate change was stopped - or greatly limited.

\section{BEGINNING AGAIN WITH A SEARCH FOR ACTIONABLE INSIGHTS}

The fierce urgency of that realization compelled me to search for ways to help. Conversations with myriad experts over the next few months revealed several insights that suggested how I might be helpful. At that time in America there was a profound lack of will - both political will and public will - to address climate change. The lack of public will - that is, the lack of public demand on government and business leaders to embrace climate solutions - was enabling a lack of political will. In turn, the lack of political action - and industry action - reinforced the apathy of the American people who were largely taking their cues about climate change from what political "elites" were (or more likely weren't) saying.

Neither of these "deficits of will" was happenstance. Rather, they were the product of well-funded, sustained, strategic communication and lobbying by the fossil fuel industry and their allies to convince Americans - especially our leaders - that climate change was either not real, not human-caused, not serious, and/or not solvable without causing arguably worse problems (like "killing the American economy"). The parallels between this situation and the tobacco use epidemic were uncanny. Indeed, research by science historians and others soon proved these parallels were not a coincidence. To forestall 
enactment of climate policies that could threaten the fossil fuel industry's profit margins, the industry was actively using the kinds of misinformation, influence peddling and other dirty tricks that were developed and perfected by the tobacco industry.

In response, my mission became to conduct social science research and use the findings of such research to counteract the corrosive influence of climate misinformation campaigns in America. To that end, my colleagues Anthony Leiserowitz (Yale) and Connie Roser-Renouf (George Mason University) and I started the Climate Change in the American Mind polling project. Through these polls we sought to reveal opportunities to promote public understanding of climate change and to build public will for climate solutions. Started in 2008 , the project is now in its 12th year, and we've conducted more than two dozen polls. These polls have proven to be incredibly productive in that they've yielded many actionable insights that, in turn, have influenced many public education campaigns.

An important premise of our polling project was that all successful public health campaigns - arguably, all successful communication campaigns feature simple clear messages, repeated often, by a variety of trusted voices. Through our polling, we've sought to better understand what the public knows and doesn't know about climate change, and who they trust as messengers, with the specific aim of improving existing public information campaigns and enabling the development of effective new initiatives - featuring simple clear messages, repeated often, by a variety of trusted voices.

At least two important insights were revealed by our first poll in 2008 . A solid majority of Americans understood and accepted the reality of climate change, although many fewer understood or accepted that human activity is the cause, and most saw it as a distant problem - distant in time (not yet), space (not here), and species (not us). The survey also revealed that two-thirds of Americans trust TV weathercasters as a source of information about climate change. Both insights proved to be directly actionable.

\section{HELPING TV WEATHERCASTERS FIND THEIR VOICE AS LOCAL CLIMATE EDUCATORS}

Seeing climate change as a distant problem is not only factually incorrect - in that climate change is already harming people in every region of the world it's also highly consequential in that problems seen as distant tend to receive little public attention or concern. We inferred that public information campaigns that emphasize the "here, now, us" qualities of climate change could help enhance public understanding and build public will. Moreover, because TV weathercasters are excellent communicators who have frequent and broad access to the public at relevant times (e.g., before, during and after weather 
events that are influenced by climate change), we inferred that they likely have considerable potential to educate the American public about the "here, now, us" qualities of climate change.

Several other colleagues and I harnessed these insights in a public education initiative called Climate Matters. Launched in 2010 as a year-long pilot-test at a local television station (WLTX) in Columbia, South Carolina, the concept was simple: TV weathercasters routinely have opportunities to teach their viewers about the ways that climate change is already changing the weather and other climate-sensitive conditions in their community, such as spring "bud burst" and "first frost" in fall. They can also present projections to reveal what is likely to occur in the future - for example, the projected annual increase in dangerously hot days in their community, 25 and 50 years from now.

We worked with the station's chief meteorologist, Jim Gandy, to prepare the educational campaign. Specifically, we identified 12 weather events that Jim felt were likely to occur over the next year (e.g., extreme precipitation events) - weather events that, if they occurred, would create a "news hook" for Jim to explain on-air how the event was part of a larger pattern of weather changes in Columbia caused by global climate change. By the end of the year-long pilot-test - which proved to be highly successful - Jim had aired 13 such stories, each approximately two minutes long. As compared to viewers of the other local TV stations, WLTX viewers came to see climate change as more of a "here, now, us" problem.

Concurrently, we surveyed TV weathercasters across America to determine their interest in educating viewers about the local implications of climate change. About half said they were interested in doing so, but relatively few actually were. Most of the weathercasters who expressed an interest in educating their viewers about climate change pointed to a handful of barriers that were preventing them from doing so on-air. Happily, the most common barriers to on-air climate reporting were problems that we felt we could help weathercasters overcome, including lack of time to prepare the stories, lack of access to broadcast quality graphics, and lack of access to climate experts.

In 2012, using this information - both the successful pilot-test of Climate Matters and the survey data showing high levels of weathercaster interest in reporting on climate change as a local problem - we began to offer weathercasters in other cities localized climate reporting resources. The response has been dramatic and remarkable. As of today (March 18, 2020), more than 800 TV weathercasters (out of the approximately 2000 weathercasters in America) are participating in the program. There is at least one participating weathercaster in every American state, and in 88 percent of U.S. TV markets. Participating weathercasters receive reporting resources via email approximately once per week - in English and/or Spanish. On-air reporting about climate change by weathercasters has increased more than 50-fold since 2012 . 
And most importantly, a growing set of evaluation studies shows that Climate Matters is making a difference: public understanding of climate change as a "here, now, us" problem is increasing most rapidly in media markets where Climate Matters materials are being used most.

The Climate Matters model is an approach to public education that may be worth replicating in other parts of the world. Indeed, it's already been adapted and is being used in Melbourne, Australia. At the very least, localized climate reporting can help people better understand the specific impacts that their community is already experiencing, and the best available projections about what the future may hold for their community. This enhanced understanding has great potential to help people, organizations and communities make better decisions about how to respond so that people and ecosystems aren't needlessly harmed.

\section{HELPING HEALTH PROFESSIONALS FIND THEIR VOICE AS CLIMATE AND CLEAN ENERGY EDUCATORS}

Our polling research and other studies conducted since 2010 strongly suggest that health professionals have a necessary and unique role to play in educating Americans about climate change, and in advocating for climate solutions. Few Americans are aware of the many ways that climate change harms the health of people living in the U.S., nor are they aware that some groups of people are more likely to be harmed than others - for example, young children, older adults, people who already suffer from various chronic illnesses, and people in low-income communities. Not surprisingly, most members of the public place high trust in health professionals as sources of information about the health relevance of climate change. Perhaps most importantly, a broad cross-section of Americans respond positively to information about the health harms of climate change and air pollution, and the health benefits of clean energy. Even Americans who are skeptical of climate change tend to respond positively to information about the health harms of fossil fuel use - because it is consistent with their pre-existing belief that fossil fuel use produces air and water pollution and is bad for people's health, unlike clean, renewable energy.

To determine if these insights were actionable, in 2014 and 2015 we surveyed the members of three U.S. medical societies: the National Medical Association (African-American physicians), the American Thoracic Society, and the American Academy of Allergy, Asthma and Immunology. A large majority of physicians in all three societies supported the idea of their medical society becoming more active in educating the public and policy-makers about the health implications of climate change and climate solutions. Many survey 
participants also said that they would like to become personally involved in such efforts.

In partnership with these and several other national medical societies, in 2017 we launched a formal collaboration called the Medical Society Consortium for Climate and Health. The mission of the Consortium is "to organize, empower and amplify the voice of America's doctors to convey how climate change is harming our health and how climate solutions will improve it." Membership in the Consortium has grown rapidly - currently including 26 national medical societies that collectively represent well over half of all American physicians, and 44 other "affiliate" member organizations that represent state medical groups, nursing societies, public health societies, health care delivery organizations, and climate science organizations. The Consortium has had considerable success in generating media coverage of climate change as a health issue: more than 1000 news stories, op-eds and letters to the editor have already been published, and interest in such stories by news media outlets appears to be escalating.

The Consortium and its member societies have also been active in conducting direct outreach to members of Congress, for example, bringing physicians to Capitol Hill to meet with their elected federal representatives. Moreover, the early successes of the Consortium have inspired the formation of several state-focused initiatives called [State] Clinicians for Climate Action. These state-focused organizations are conducting direct outreach to governors and state legislators, and in some cases local government officials.

The Consortium has also helped create broader health coalition efforts. In 2019, for example, the Consortium helped pull together more than 150 other health organizations to write, endorse and issue a Climate, Health and Equity Policy Action Agenda. The agenda identifies ten policies that protect human health and the Earth's climate, and calls on government, business, and civil society leaders, elected officials, and candidates for office to recognize climate change as a health emergency and to work across government agencies and with communities and businesses to prioritize the recommended policies. This policy action agenda is an important step forward because it represents a consensus view from a wide cross-section of the American health community about the policy actions they are asking government and business leaders to take, as well as the actions that they are asking themselves and all other health organizations to take.

My colleagues and I aspire to leverage these important actions by the American medical community - and the broader health community in the U.S. - to inspire health professionals in other nations to use their trusted voices to advocate for policies that will advance climate, health and equity goals in their nations. Ultimately, my vision is a global climate, health and equity campaign, led by health professionals, to support, defend and strengthen the goal of the 
Paris Agreement - limiting global warming to no more than $2{ }^{\circ} \mathrm{C}$, ideally no more than $1.5^{\circ} \mathrm{C}$ - because, arguably, it is humanity's most important public health goal.

\section{CONCLUSION}

"No one can do everything, but everyone can do something." This saying attributed to various people, although I first heard it from primatologist and conservation champion Jane Goodall - holds much meaning for me. The work I've described here was not mine alone - indeed, I've collaborated with dozens or perhaps hundreds of people on this work. The question I urge you to consider is: What "something" can you start - or support - that is likely to be most helpful in averting a sustained global public health catastrophe from climate change? I urge you to give that "something" your best shot. 